\title{
21. IN SITU STRESS AT THE CÔTE D'IVOIRE-GHANA MARGINAL RIDGE FROM FMS LOGGING IN HOLE 959D ${ }^{1}$
}

\author{
Maria $\mathrm{Ask}^{2}$
}

\begin{abstract}
The orientation of the in situ stress between 550 and 925 meters below seafloor in Hole 959D has been derived from the analysis of caliper and electrical images of Formation MicroScanner data. Because of a high hole deviation $\left(5^{\circ}-13^{\circ}\right)$, drill pipe wear has enlarged the hole in a northerly direction. As a result, the four-arm caliper analyses cannot distinguish between mechanically and stress induced borehole elongations. The FMS data show that one of the principal stresses is parallel to the borehole axis and that mainly tensile wall fractures have formed in the borehole wall. The tensile wall fractures demonstrate a $168^{\circ} \pm 8^{\circ} \mathrm{N}$ weighted mean orientation of the maximum horizontal stress. The upper $750 \mathrm{mbsf}$ of the borehole comprises the majority of the tensile wall fractures, whereas they only occur sporadically below this depth. The change in the downhole distribution of fractures coincides with the transition from weaker to more compacted, stronger sedimentary rock. Furthermore, the integration of seismic and physical properties data suggests that this depth corresponds to the boundary between passive margin evolution and continent/ocean transform faulting.

The orientation of the maximum horizontal stress in Hole 959D is almost perpendicular to the east-west maximum horizontal stress orientation of the first-order stress province in western and north central Africa. Through comparisons with (1) the orientations of the maximum horizontal stress in Hole 959D, (2) the maximum horizontal stress of three focal mechanisms from earthquakes in Ghana, and (3) the strike of the continental margin, it is suggested that lateral strength contrasts across the Côte d'Ivoire-Ghana Transform Margin are the most probable source for the observed stress orientations. It is further suggested that sediment loading and lateral variation in crustal thickness and density may only have a minor influence on the stress field in this area.
\end{abstract}

\section{INTRODUCTION}

The Côte d'Ivoire-Ghana (CIG) Transform Margin was investigated during Ocean Drilling Program (ODP) Leg 159 (Fig. 1). Transform faults are the third major category of plate boundaries (Isacks et al., 1968), and they occur in both continental and oceanic crust. One objective of Leg 159 was to understand better the different structural, thermal, and sedimentary processes that operate at the transform margin.

The morphology and structure of the CIG Transform Margin are well known from several geophysical cruises and submarine dives (cf. Mascle et al., 1996). Two main features have been identified (Fig. 2): (1) the continent-ocean transition is steep and narrow $(20-30 \mathrm{~km})$, and (2) the transform margin is bounded by the well-expressed Côte d'Ivoire-Ghana Marginal Ridge (CIGMR) that is the southernmost part of the continental domain. The northern flank of the CIGMR is filled with sediments of the Deep Ivorian Basin, whereas its southern flank towers by about $3000 \mathrm{~m}$ over the Gulf of Guinea Abyssal Plain (Fig. 2B). Both the Deep Ivorian Basin and CIGMR were generated as a consequence of Early Cretaceous rifting of the northern South Atlantic. The CIGMR is believed to have been influenced by additional tectonic and thermal processes related to syn-transform motion. The CIGMR connects laterally with the Romanche Fracture Zone, which offsets the Mid-Atlantic Ridge by $945 \mathrm{~km}$ and where the transform motion still is active. Site 959 is situated in southernmost Deep Ivorian Basin, about $3 \mathrm{~km}$ north of the crest of the CIGMR. This study is mainly devoted to investigating the orientation of in situ stress in Hole 959D.

The orientation of in situ stress in the lithosphere is due to a superposition of local, regional, and global stress sources. Compilations of global and regional stress data, such as the World Stress Map

${ }^{1}$ Mascle, J., Lohmann, G.P., and Moullade, M. (Eds.), 1998. Proc. ODP, Sci. Results, 159: College Station, TX (Ocean Drilling Program).

${ }^{2}$ Engineering Geology, Royal Institute of Technology, S-100 44 Stockholm, Sweden.ask@ce.kth.se
(WSM; Zoback, 1992) are important for the interpretation of lithospheric dynamics and for the understanding of plate driving forces. For example, the compilations of stress data have shown that large areas within the lithospheric plates often are characterized by uniformly oriented horizontal in situ stress (i.e., first-order stress provinces). Zoback (1992) identified a first-order stress province in western and north central Africa that has an approximately east-west orientation of the maximum horizontal in situ stress $\left(\mathrm{S}_{\mathrm{H}}\right)$. Figure 1 shows a compilation of stress data from the equatorial Atlantic and surroundings. These stress observations are generally obtained from fault plane solutions (Zoback, 1992; Suleiman et al., 1993; Harvard Centroid Moment Tensor [CMT] catalog). The influence from local and regional stress sources may generate second-order stress patterns that disturb the first-order stress field. Zoback (1992) presented a number of potential sources that can generate second-order stress patterns near continental margins, they are (1) sediment loading, (2) lateral variation in crustal thickness and density, and (3) lateral strength contrasts.

This is the first paper that reports on the orientation of in situ stress from borehole breakouts and tensile wall fractures in the CIG Transform Margin. The electrical conductivity and borehole geometry were measured by the Formation MicroScanner (FMS) tool between 550 and 925 mbsf in Hole 959D. The purpose of this paper is, first, to determine the orientation of $\mathrm{S}_{\mathrm{H}}$ in Hole 959D from a detailed analysis of the FMS data. The results will be discussed with respect to the lithostratigraphy, structures, and physical properties of the sediment. Second, the observed mean $\mathrm{S}_{\mathrm{H}}$ orientation will be compared with the first-order stress province of western and north central Africa, and potential sources for the observed stress field will be discussed. Finally, data presented are incorporated into the WSM (Zoback, 1992).

\section{SUMMARY OF DATA}

In this section, the drilling results from Hole 959D are briefly summarized. The complete drilling results are available in the site re- 
Figure 1. Orientation of maximum horizontal stress $\left(\mathrm{S}_{\mathrm{H}}\right)$ from the Equatorial Atlantic and surroundings. The location of ODP Leg 159 and Figure 2A is indicated by the square. The symbol associated with each data point indicates the type of stress indicator. Focal mechanism data come from three different sources: data from the World Stress Map are shown in black, data from Suleiman et al. (1993) are shown in white, and data from the Harvard Centroid Moment Tensor catalog are shown in gray. Stress data from other stress indicators come from the World Stress Map. Data qualities of stress measurements are assigned according to the World Stress Map quality ranking scheme (Zoback, 1992), and the length of the bars attached to each data point is a measure of its quality (A, B, or C). The new data point from Hole 959D is included in the square. However, the length of the bar is not ranked with respect to its quality because no ranking scheme for tensile wall fractures has been constructed as yet. CIGTM = the Côte d'Ivoire-Ghana Transform Margin, and RFZ = the Romanche Fracture Zone.

Figure 2. A. Location of Site 959 and the Côte d'IvoireGhana Marginal Ridge (CIGMR; after Shipboard Scientific Party, 1996; see location on Fig. 1). B. Northsouth trending migrated seismic Line MT02 across the Deep Ivorian Basin, Côte d'Ivoire-Ghana Marginal Ridge and Gulf of Guinea abyssal plain (after Shipboard Scientific Party, 1996; see location on Fig. 2A).
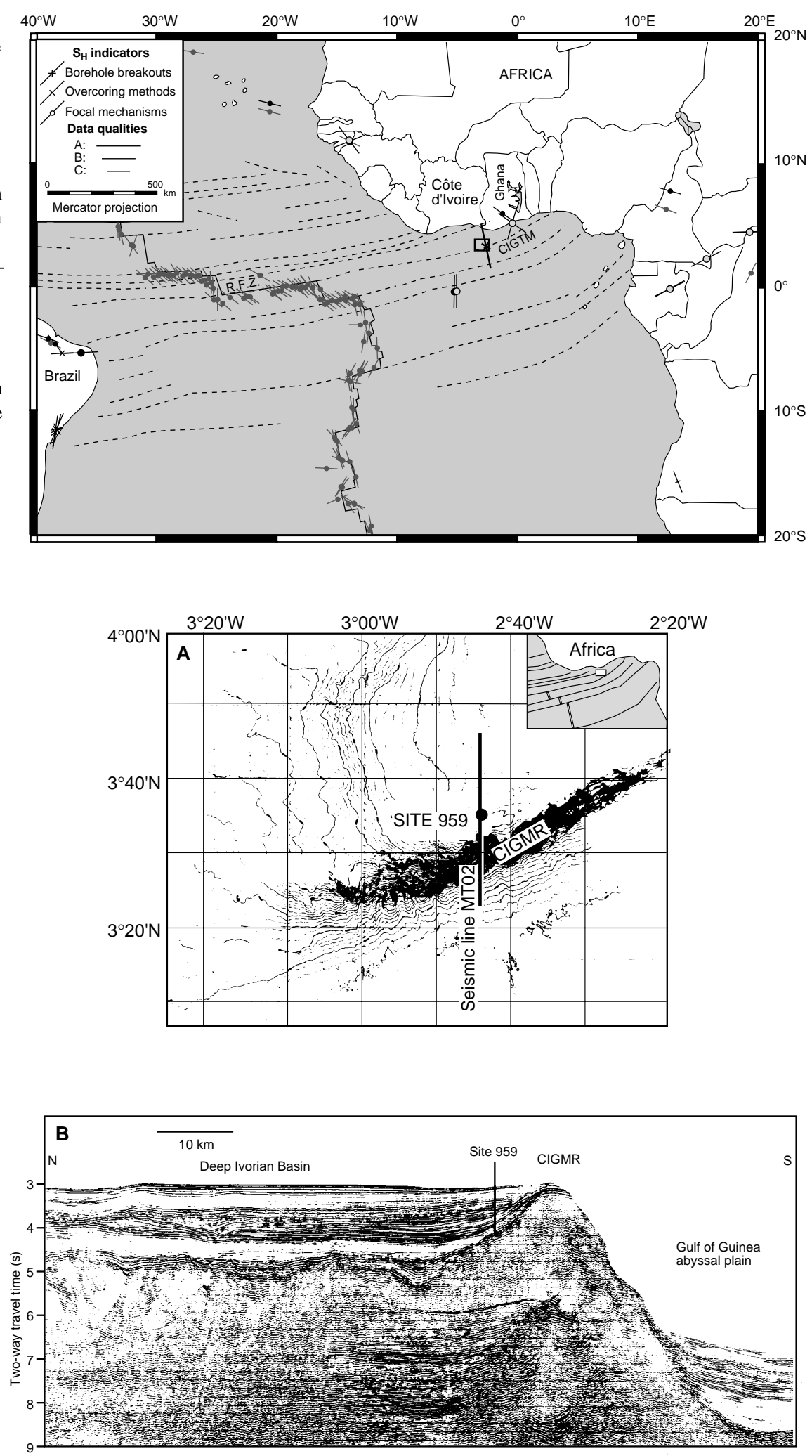
port chapter of Site 959 (Shipboard Scientific Party, 1996). This is followed by a short presentation of existing stress data in western Africa and the equatorial Atlantic.

\section{Drilling Results}

Hole 959D is located in $2102 \mathrm{~m}$ water depth on the southern shoulder of the Deep Ivorian Basin, where the total sediment thickness is about $3000 \mathrm{~m}$ (Fig. 2). Figure 3 shows main seismic units, lithostratigraphy, and well-log and physical properties data that were obtained in Hole 959D. The master column shows core recovery, and the generalized lithology of the cored sediment types and their rela- tive proportions. The hole geometry and distribution of fractures detected from the FMS images (see below) are plotted for comparison.

\section{Site Geophysics}

Basile et al. (1993) defined six seismic units (A-F) that can be correlated to different stages in the evolution of the CIG Transform Margin. An integration between the seismic record of Equasis multichannel Line MT02 (Fig. 2B) and physical properties data were made in the "Site Geophysics" section of Shipboard Scientific Party (1996). This integration suggests that one major reflector at $750 \mathrm{mbsf}$ occurs within the study interval. This reflector is thought to corre-

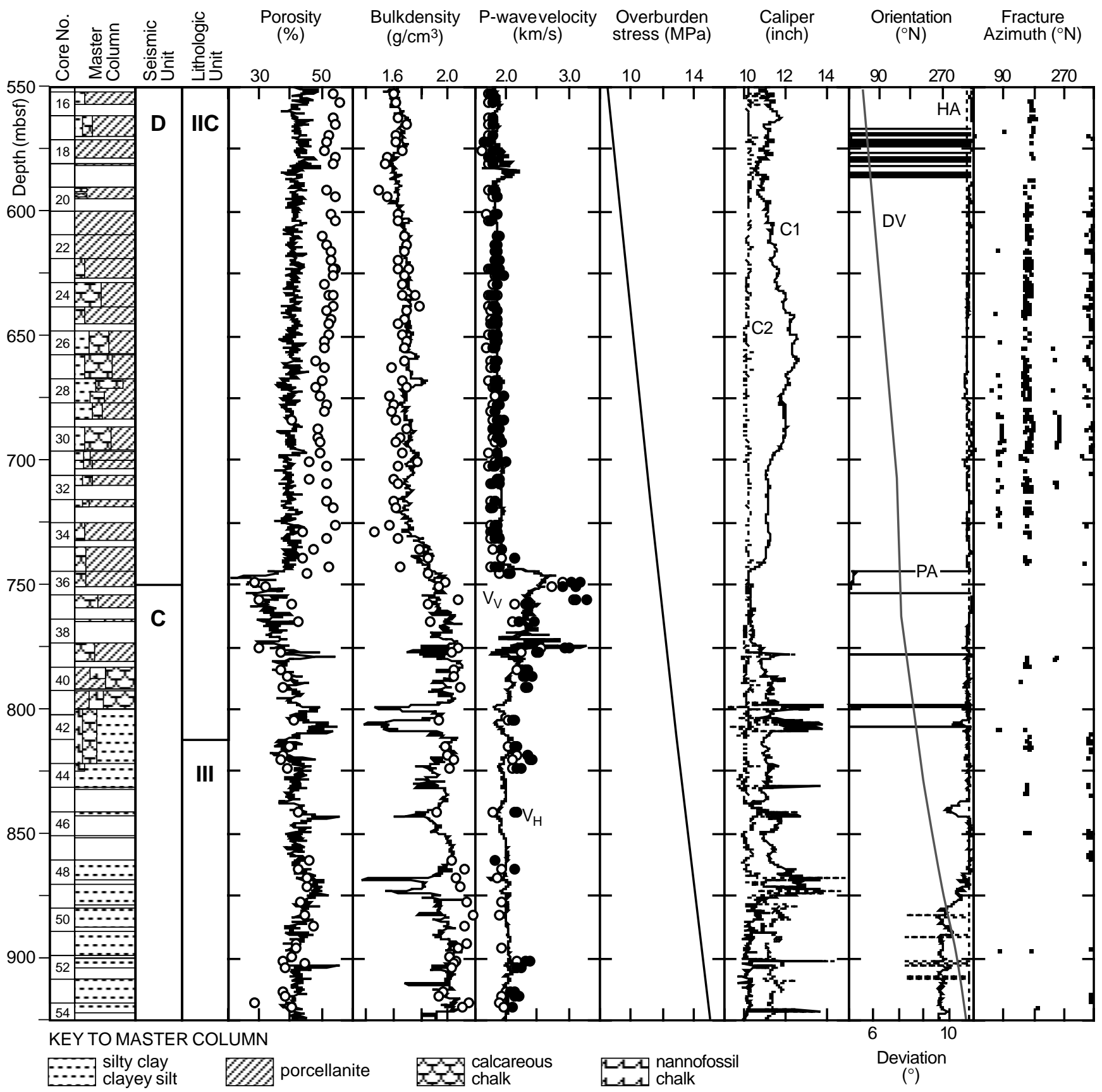

Figure 3. Drilling results from Hole 959D from 550 to $925 \mathrm{mbsf}$. Solid lines show logging data, and data points show discrete physical properties data. $\mathrm{V}_{\mathrm{V}}$ (open circles) $=$ vertical $P$-wave velocity, $\mathrm{V}_{\mathrm{H}}$ (solid circles) $=$ horizontal $P$-wave velocity, $\mathrm{C} 1=$ caliper arm pair $1, \mathrm{C} 2=$ caliper arm pair $2, \mathrm{HA}$ is hole azimuth, DV $=$ hole deviation, and PA = Pad 1 azimuth. 
spond to the change from continental/ocean transform faulting to passive margin evolution.

\section{Lithostratigraphy}

The sequence between 550 and 812.3 mbsf corresponds to lithologic Subunit IIC. It consists of porcellanite that, because of alteration, is virtually barren of all siliceous flora and fauna. Porcellanite occurs with a distinct color banding ranging from $10 \mathrm{~cm}$ to $2.5 \mathrm{~m}$ thick, which reflects variation in the organic matter and pyrite content, and in the degree of bioturbation. Micrite occurs at various levels within this subunit, but systematically increases in the lower part. Because of an increase in carbonate content below $600 \mathrm{mbsf}$, the lithology changes from porcellanite with clay, to porcellanite with micrite, and subsequently to porcellanite nannofossil chalk. The age of sediment within the subunit ranges from early Miocene to late Paleocene.

Lithologic Unit III is encountered in the sequence between 812.3 and 925 mbsf. The unit is composed of black claystone and claystone with nannofossils. Alternating beds of late Paleocene claystone, nannofossil claystone, and micritic claystone are encountered in the upper $19.3 \mathrm{~m}$ of the unit. The interval from 831.6 to $898.2 \mathrm{mbsf}$ is dominated by grayish black massive claystone. This interval is early Paleocene to Maastrichtian in age and is slightly to moderately bioturbated. Claystone, glauconitic claystone with pyrite, and claystone with pyrite of Maastrichtian age are observed down to 925 mbsf.

\section{Structural Geology}

Structures observed between 550 and 925 mbsf in Hole 959D include bedding planes, microfaults, and veins. The upper $50 \mathrm{~m}$ of the interval is characterized by shallowly dipping beds $\left(<12^{\circ}\right)$. Below, there is a general increase in bedding dips with depth, to about $25^{\circ}$ at $925 \mathrm{mbsf}$. Apparently anastomozing faults (i.e., interlacing faults) affect mainly diatomites, porcellanites and micrites of lithologic Subunit IIC. Planar normal faults are well developed, and veins are relatively common in the porcellanite of this subunit. Planar normal faults are well developed in the black claystone of Unit III, and thin thread-like veins of pyrite are commonly observed.

\section{Physical Properties and Downhole Measurements}

Discrete and continuous measurements of porosity, bulk density and $P$-wave velocity were collected from cores and downhole logs, respectively (Fig. 3). The discrete measurements of porosity show a decreasing trend $(55 \%-50 \%)$ from 550 to 700 mbsf, whereas the continuous measurements of porosity generally decrease from $45 \%$ to $40 \%$. This difference is mainly attributed to porosity rebound in the cores because of the removal of the overburden pressure. It is followed by a 50 -m-long section with more scattered values $(44 \%-$ $54 \%$ ), that partly overlaps the data from the log measurements. Both the discrete and continuous measurements of bulk density and $P$ wave velocity have rather constant values down to $750 \mathrm{mbsf}$. The bulk density ranges generally from 1.55 to $1.75 \mathrm{~g} / \mathrm{cm}^{3}$ and the $P$-wave velocity increases from about 1.8 to $1.9 \mathrm{~km} / \mathrm{s}$. There is a more or less well pronounced offset in the three properties at about $750 \mathrm{mbsf}$, which corresponds to the boundary between seismic Units D and C.

Below 750 mbsf, the porosity data from both discrete and continuous measurements generally demonstrate a good correspondence. This suggests that the removal of the overburden pressure had little influence on the porosity in the cores, and thus that the sections are well lithified. The porosity drops to the minimum value of $28 \%$ at 750 mbsf, which is followed by decreasing values to $46 \%$ at about $880 \mathrm{mbsf}$. The last $50 \mathrm{~m}$ of the interval is characterized by decreasing porosity values to about $40 \%$ at 925 mbsf. Values of bulk density from discrete measurements increase slowly to the maximum of 2.2 $\mathrm{g} / \mathrm{cm}^{3}$ at 880 mbsf. Scattered values between 1.85 and $2.2 \mathrm{~g} / \mathrm{cm}^{3}$ are measured from 880 to 925 mbsf. There is generally good correspondence between core and $\log$ data of bulk density and $P$-wave velocity in sections with good recovery. Exceptions to this trend occur in intervals with low recovery and in sections with increased borehole diameter (i.e., washouts). Minimum values $\left(\approx 1.5 \mathrm{~g} / \mathrm{cm}^{3}\right)$ are measured in two big washout zones from 795 to $812 \mathrm{mbsf}$ and 865 to $885 \mathrm{mbsf}$, respectively. The continuous measurements of bulk density are derived from a nuclear logging tool that has a shallow depth of investigation, and hence is sensitive to washouts. Higher values (2.1 to 3.1 $\mathrm{km} / \mathrm{s}$ ) of $P$-wave velocity from discrete measurements occur from 750 to 790 mbsf. Below, the log measurements are rather constant and range generally from 1.9 to $2 \mathrm{~km} / \mathrm{s}$. The discrete measurements are consistently greater down to $850 \mathrm{mbsf}$, whereas they mostly are of comparable value from 850 to $925 \mathrm{mbsf}$. The $P$-wave velocity in the cores is measured in both the horizontal and vertical direction. In general, the $P$-wave velocities in the horizontal direction are greater than those in the vertical direction.

The total vertical stress is often assumed to be equal to the weight of overlying sediments. The weight of overlying sediments is calculated from $\rho g z$ where $\rho$ is the bulk density, $g$ is the gravity force $(9.8$ $\mathrm{m} / \mathrm{s}^{2}$ ), and $z$ is the depth. Because of the good correspondence between the core and $\log$ data, I used bulk density and depth values from both data sets in the calculation. However, only core data has been used for the calculation of the vertical stress from 0 to $395 \mathrm{mbsf}$ as this section was not logged. Figure 3 shows that the estimated total vertical stress increases linearly from 9 to $16 \mathrm{MPa}$ over the investigated depth interval.

\section{In Situ Stress Data}

Figure 1 is a compilation of data from three different sources: (1) the WSM, (2) earthquake moment tensors for western Africa determined by Suleiman et al. (1993), and (3) the Harvard CMT catalog.

The WSM is a compilation of stress data from several different methods of stress measurement, although earthquake focal mechanisms are most abundant. The data from Suleiman et al. (1993) were determined by seismic waveform inversions as part of a detailed study of seven earthquakes and waveform inversions. After the data are converted to $\mathrm{P}$ and $\mathrm{T}$ axes, they are ranked from $\mathrm{A}$ to $\mathrm{D}$ according to the WSM ranking scheme (Zoback, 1992). It should be noted that a double earthquake was recorded at $0.13^{\circ} \mathrm{W}, 5.18^{\circ} \mathrm{N}$, near the Leg 159 area, and both focal mechanisms are shown to be quite different $\left(16^{\circ}\right.$ and $305^{\circ} \mathrm{N}$, respectively). Table 1 lists data from the WSM and Suleiman et al. (1993). There is some redundancy between the two data sets. Suspected duplicates are marked in Table 1, whereas the complete data set is shown in Figure 1.

The CMT data are primarily located along the mid-Atlantic Ridge. Most of the data indicate strike-slip transform earthquakes. According to Zoback (1992), CMT data should generally be assigned to quality $\mathrm{C}$ if no additional study of the data was made. The main reason is that the resolution of the CMT inversion is relatively poor for the vertical dip-slip components of faulting in shallow focus events (Sipkin, 1986). At present, CMT data from plate boundaries are not incorporated into the WSM.

\section{THEORY FOR BOREHOLE BREAKOUTS AND TENSILE WALL FRACTURES}

\section{Borehole Breakouts}

Radial, circumferential and shear stresses $\left(\sigma_{\mathrm{r}}, \sigma_{\theta}, \tau_{\mathrm{r} \theta}\right.$, respectively) are formed around a borehole as it is being drilled. Anisotropy in the tectonic far-field principal stresses, and differences in temperature and properties of the formation and the drilling fluid result in 
Table 1. Stress data from the World Stress Map and Suleiman et al. (1993).

\begin{tabular}{lcrlccc}
\hline Longitude & Latitude & $\mathrm{S}_{\mathrm{H}}$ & Type & Quality & Regime & Source \\
\hline 19.363 & 4.463 & 89 & FMS & B & SS & WSM $^{1}$ \\
19.363 & 4.463 & 268 & FMS & B & SS & Suleiman $^{1}$ \\
15.9 & 2.276 & 243 & FMS & B & SS & Suleiman \\
13.5 & -16 & 158 & OC & C & NF & WSM \\
12.95 & 7.85 & 106 & FMS & C & TF & WSM \\
12.808 & -0.283 & 60 & FMS & B & SS & WSM $^{2}$ \\
12.808 & -0.283 & 241 & FMS & B & SS & Suleiman $^{2}$ \\
-0.13 & 5.18 & 305 & FMS & B & SS & Suleiman $^{2}$ \\
-0.13 & 5.18 & 16 & FMS & B & SS & Suleiman $^{\text {WSM }}$ \\
-1 & 6 & 125 & FMS & C & SS & WSM \\
-4.7 & -0.4 & 180 & FMS & B & TF & Suleiman $^{3}$ \\
-4.89 & -0.45 & 1 & FMS & B & TF & WSM \\
-13.529 & 11.866 & 67 & FMS & B & SS & WSM \\
-13.54 & 11.98 & 143 & FMS & B & SS & Suleiman $^{4}$ \\
-20.1 & 15 & 104 & FMS & C & SS & WSM \\
-35.75 & -5.55 & 87 & FMC & B & SS & WSM \\
-37.29 & -5.54 & 87 & BO & C & U & WSM \\
-37.813 & -11.833 & 23 & BO & A & U & WSM \\
-37.834 & -11.861 & 14 & BO & A & U & WSM \\
-37.866 & -11.914 & 8 & BO & B & U & WSM \\
-37.98 & -4.81 & 142 & FMC & C & SS & WSM \\
-38.4 & -4.3 & 109 & FMS & C & SS & WSM \\
& & & & & &
\end{tabular}

Note: Type, Quality, and Regime notation are the same as within the World Stress Map (Zoback, 1992). North latitude has positive values, south latitude has negative values, east longitude has positive values, and west latitude has negative values. Suspected redundancies between the two data sets are marked by $1,2,3,4$

stress concentration around the borehole. If the stress concentration exceeds the rock strength, borehole breakouts will form (Bell and Gough, 1979) (Fig. 4A). Usually, the breakouts are diametrically opposed at the borehole wall, and the wall is generally rough inside the breakout and smooth outside the breakout. The length of a breakout varies generally from less than a meter to several tens of meters (e.g., Shamir and Zoback, 1992; Brudy et al., 1997).

Bell and Gough (1979) presented an interpretation of breakouts that is valid for near-vertical boreholes where (1) the principal total stresses are assumed to be vertical $\left(\mathrm{S}_{\mathrm{v}}\right)$ and horizontal $\left(\mathrm{S}_{\mathrm{H}}\right.$ and $\left.\mathrm{S}_{\mathrm{h}}\right)$, and (2) the magnitudes of horizontal stresses are anisotropic. Their analysis is based on the equations by Kirsch (1898). Zoback et al. (1985) expanded this equation by using effective principal stress (i.e., total stress minus pore pressure $S_{H}, S_{h}$ ), and they also account for the effect of the difference in pressure between the drill fluid and the rock formation $(\Delta \mathrm{P})$. The circumferential stress concentration at the borehole wall is then:

$$
\sigma_{\theta}=S_{H}^{\prime}+S_{h}^{\prime}-2 \cdot\left(S_{H}^{\prime}-S_{h}^{\prime}\right) \cdot \cos (2 \theta)+\Delta P
$$

where $\theta$ is the angle from the direction of the maximum stress $\left(\mathrm{S}_{\mathrm{H}}\right.$; Fig. 4A). Maximum stress concentration occurs at $\theta=90^{\circ}$ and $\theta=$ $270^{\circ}$, which is parallel to the direction of minimum horizontal stress $\left(\mathrm{S}_{\mathrm{h}}\right)$. The theory for borehole breakout analysis has also been applied for inclined boreholes (e.g., Mastin, 1988; Brudy and Zoback, 1993; Péska and Zoback, 1995).

\section{Tensile Wall Fractures}

The stress concentration around the borehole discussed above can produce tension in some parts of the borehole wall, and tensile wall fractures may form in the orientation parallel to $S_{H}$ (Fig. 4B). These fractures have been reported to be fine-scale and shallow features that occur on opposite sides of the borehole wall with a length from 0.1 to $1 \mathrm{~m}$ (Brudy and Zoback, unpubl. data; Brudy et al., 1997). Péska and Zoback (1995) presented two types of tensile wall fractures, namely, those that are parallel to the borehole wall and those with an en echelon pattern of fine wall fractures that are inclined toward the borehole axis. If the tensile wall fracture is oriented parallel to the bore-
A

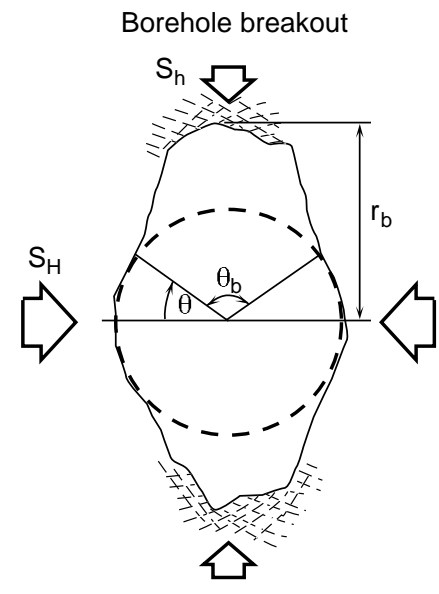

B

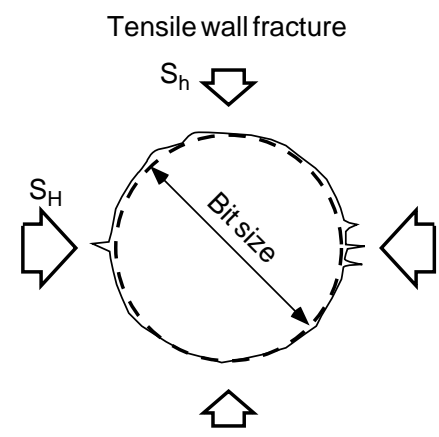

Figure 4. Stress-induced borehole cross sections. A. Borehole breakouts. B. Tensile wall fractures (modified after Hillis and Williams, 1992). $\mathrm{S}_{\mathrm{H}}=$ the maximum horizontal stress, $S_{h}=$ the minimum horizontal stress, $r_{b}=$ the breakout depth and $\theta_{\mathrm{b}}=$ the breakout angle.

hole axis, they suggest that the borehole axis coincides with one principal stress. On the other hand, they suggested that an echelon pattern and inclined fractures are indications of a principal stress orientation that is non-parallel to the borehole axis.

Tensile wall fractures are not associated with lost circulation like drilling-induced fractures that occur when the fluid pressure in the well exceeds the principal stress (Apel et al., 1993, Zoback et al., 1995). Tensile wall fractures can be formed when the elastic stress concentration is slightly compressive, if additional tensile stresses are present. One source of tensile stress is the cooling of the rock at the borehole wall due to the circulation of cold drilling fluid. Moos and Zoback (1990) noted that this tends to occur in deep ODP drill holes as the in situ temperatures in these holes are generally higher than the temperature of the drill fluid. After Stephens and Voight (1982) and Ritchie and Sakakura (1956), this thermally induced stress is expressed as

$$
\sigma_{T}=-\frac{\alpha \cdot E \cdot \Delta T}{1-v}
$$

where $\alpha$ is the thermal compressibility, $E$ is Young's modulus, $\Delta T$ is the temperature difference between the formation and drill-fluid temperature, and $v$ is Poisson's ratio. Brudy and Zoback (1993) calculated that this leads to about $1 \mathrm{MPa}$ additional tensile stress per 
$1{ }^{\circ} \mathrm{C}$ cooling in common rock types. Brudy and Zoback (unpubl. data) wrote that tensile failure will occur at the borehole wall when the stress concentration exceeds tensile strength (T). By using effective principal stresses $\left(S_{H}^{\prime}\right.$ and $\left.S_{h}^{\prime}\right)$, their formula becomes

$$
\sigma_{\theta}=S_{H}^{\prime}+S_{h}^{\prime}-2 \cdot\left(S_{H}^{\prime}-S_{h}^{\prime}\right) \cdot \cos (2 \theta)+\sigma_{T}-2 \cdot P_{b} \leq T,
$$

where $\sigma_{\mathrm{T}}$ is thermally induced stress from Equation 2 and $\mathrm{P}_{\mathrm{b}}$ is the mud pressure.

\section{DOWNHOLE MEASUREMENTS WITH THE FMS}

The FMS tool consists of four orthogonally positioned caliper arms with micro-resistivity electrodes mounted on each pad. The pads are mounted in sequence, Pads 1 to 4 . Pad 1 is the reference pad from which the orientation with respect to north is measured. The tool collects two types of data, namely, conventional four-arm caliper data and FMS images of the small-scale variations in the electrical conductivity.

\section{Four-Arm Caliper Device of FMS Tool}

The four-arm caliper records the distance between each opposite arm pair $(\mathrm{C} 1$ and $\mathrm{C} 2)$ and the orientation of the tool with respect to the north and to the vertical. Measurements are made during pulling the tool up the borehole, with a vertical sampling frequency of one measurement per $152 \mathrm{~mm}$. The four-arm caliper tool will only record a borehole elongation if it has a width greater than the pad width and a length greater than the pad length. The tool spirals slowly while being pulled up as a result of the tension and twisting of the cable. This rotation normally stops if an elongation zone with a greater width and length than that of the pad dimensions is reached as the caliper becomes fixed in the elongated grooves. The program used for the breakout analyses shows the downhole variation in caliper readings ( $\mathrm{C} 1$ and $\mathrm{C} 2)$ and orientation data. Sections with breakout candidates are selected, and the data are stacked over this depth interval in so-called contour and difference plots. This gives an impression of the mean borehole contour within the interval.

Plumb and Hickman (1985) postulated five criteria for separating between stress-induced borehole elongations (borehole breakouts) and mechanically induced ones (e.g., drill pipe wear and washouts). Their breakout criteria (listed below) have been slightly modified for this study, mainly because of limitations in the breakout analyzing program, which requires a certain number of data points to produce a contour and difference plot.

Breakout criteria used in this study:

1. The rotation of the logging tool has to stop completely.

2. The difference in caliper readings in breakouts should exceed $12 \mathrm{~mm}$.

3. The smaller caliper reading has to be close to bit size, or if the smaller caliper reading is greater than bit size, it should exhibit less variation than the larger caliper.

4. The length of the breakout has to exceed $1 \mathrm{~m}$.

5. The direction of elongation must not consistently coincide with the azimuth of the high side of the borehole wall when the borehole deviates from the vertical.

Drill-pipe wear often produces a mechanically induced elongation in boreholes with a deviation larger than $1^{\circ}$ from the vertical (Fuchs and Clauss, 1987). By entering cut-off values into the breakout analyzing program, the difference between Pad 1 and hole azimuths is calculated for all sections of the borehole that has a deviation of more than $1^{\circ}$. When the difference between the two data sets is less than $10^{\circ}$, the data are ignored (cf. "wrong values" in Fig. 5).

The data collected from the breakout analyzing program was entered into a dedicated program that calculates statistics on directional data according to Mardia (1972). Each individual breakout candidate is weighted by its own length to enhance dominant $S_{H}$ orientations, and the weighted statistical mean $\mathrm{S}_{\mathrm{H}}$ orientation and the standard deviation are calculated in the program.

\section{FMS Sensor of FMS Tool}

The FMS-tool maps the electrical conductivity of the borehole wall using an array of small, pad-mounted electrodes (Ekstrom et al., 1987). The configuration used during Leg 159 contained 16 buttonshaped electrodes on each of four orthogonal pads to generate the FMS images. Each pad covers $24^{\circ}$ of the borehole wall for the 251mm-sized bit (9.88 in). Thus, the four pads cover about $27 \%$ of the borehole wall. During logging, a current flows from each electrode to a single return electrode located at the top of the tool. The button current is recorded as a series of curves that represent relative changes of micro-conductivity in the rock caused by either (1) electrolytic conduction in the pore space or (2) cation exchanges on the surfaces of clay minerals. The current intensity is converted into variableintensity FMS images. The vertical resolution is about $2.5 \mathrm{~mm}$, although thinner features of high conductivity may be detected. Because of the electrode geometry, the pads have a very shallow depth of investigation (a few centimeters beyond the borehole wall) (Pezard et al., 1992).

The downhole images of each pad, oriented in space with respect to the north, are shown by the analyzing program. It is possible to obtain the strike and dip of a plane by pointing with the cursor and selecting interesting sections. For this analysis, only vertical features are of interest. After completion of analyzing the FMS data, statistics on directional data by Mardia (1972) are used to obtain a weighted statistical mean $\mathrm{S}_{\mathrm{H}}$ orientation for the data.

\section{RESULTS}

The information from the FMS tool includes four-arm caliper and FMS sensor data. The results from the four-arm caliper analysis are presented first to show the occurrence of prominent borehole elongations. This is followed by a presentation of the results from the FMS sensor to show the existence of small-scale borehole elongations and fractures. The interpretation of the orientation of in situ stress is discussed in the in situ stress section of this chapter.

\section{Four-Arm Caliper Device of FMS Tool}

Figure 3 shows that caliper readings vary with depth. The interval from 550 to $750 \mathrm{mbsf}$ has rather constant values of the smaller caliper $(\mathrm{C} 2=\approx 254 \mathrm{~mm}$ or $10 \mathrm{in})$, which is close to the bit size $(251 \mathrm{~mm}$ or $9.88 \mathrm{in}$ ), and two bell-shaped trends in the larger caliper (C1). This is followed by a 25-m-long section with similar values of $\mathrm{C} 1$ and $\mathrm{C} 2$ (254-267 mm or 10-10.5 in). Below $775 \mathrm{mbsf}$, the smaller caliper is often fairly close to bit size, but peak values (washouts) up to $381 \mathrm{~mm}$ (15 in) are repeatedly encountered. The larger caliper has a similar peak value distribution to the smaller one, and is generally about 279 $\mathrm{mm}$ (11 in). The size of $\mathrm{C} 1$ down to $775 \mathrm{mbsf}$ is reflected in variations in the lithology in that (1) increases in $\mathrm{C} 1$ coincide with increases in the clay and micrite content, and (2) C1 values of $\sim 279 \mathrm{~mm}$ or less $(\leq 11 \mathrm{in})$ are measured in sections that are predominantly composed of porcellanite (60\% or more) (Fig. 3). 
A

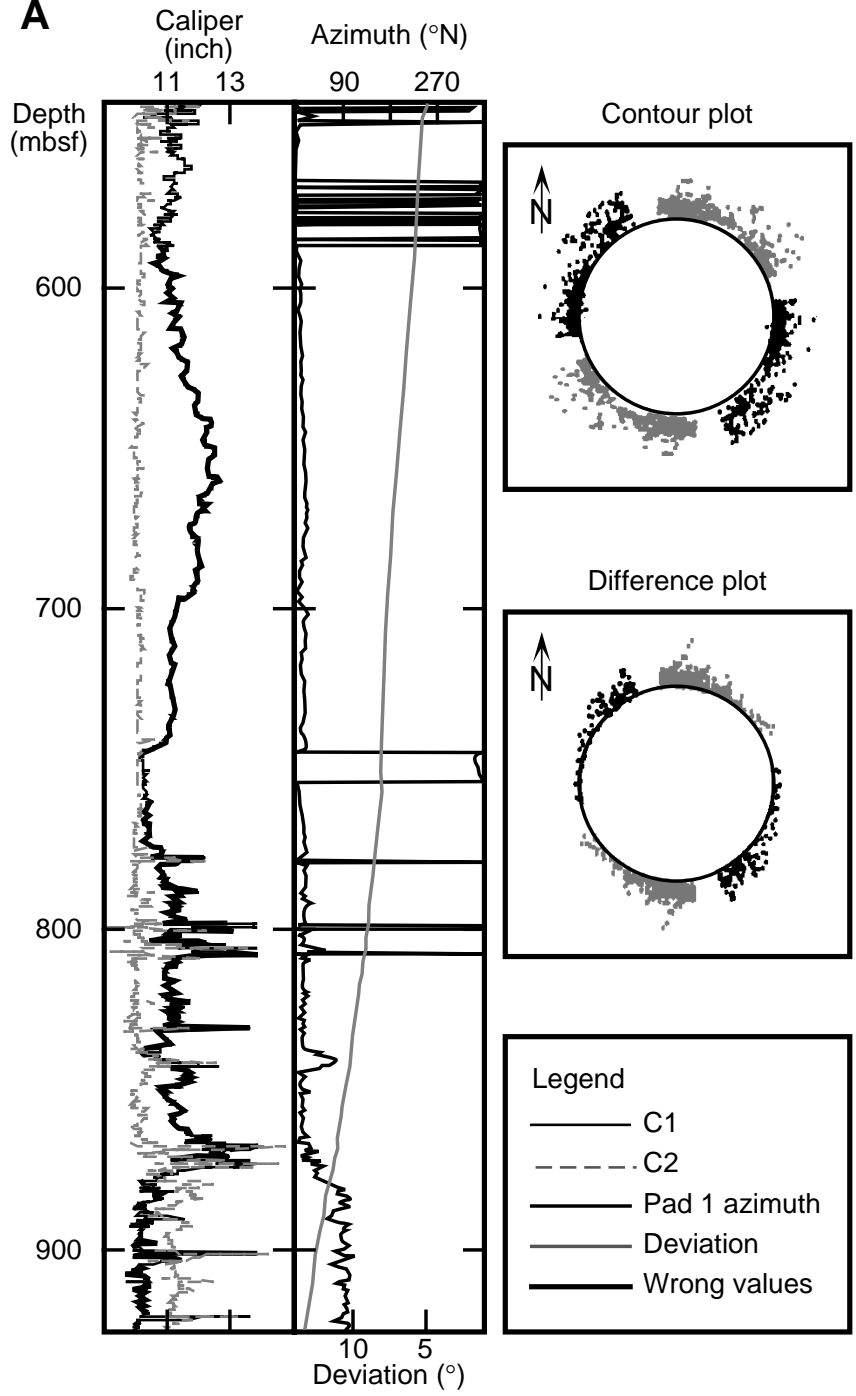

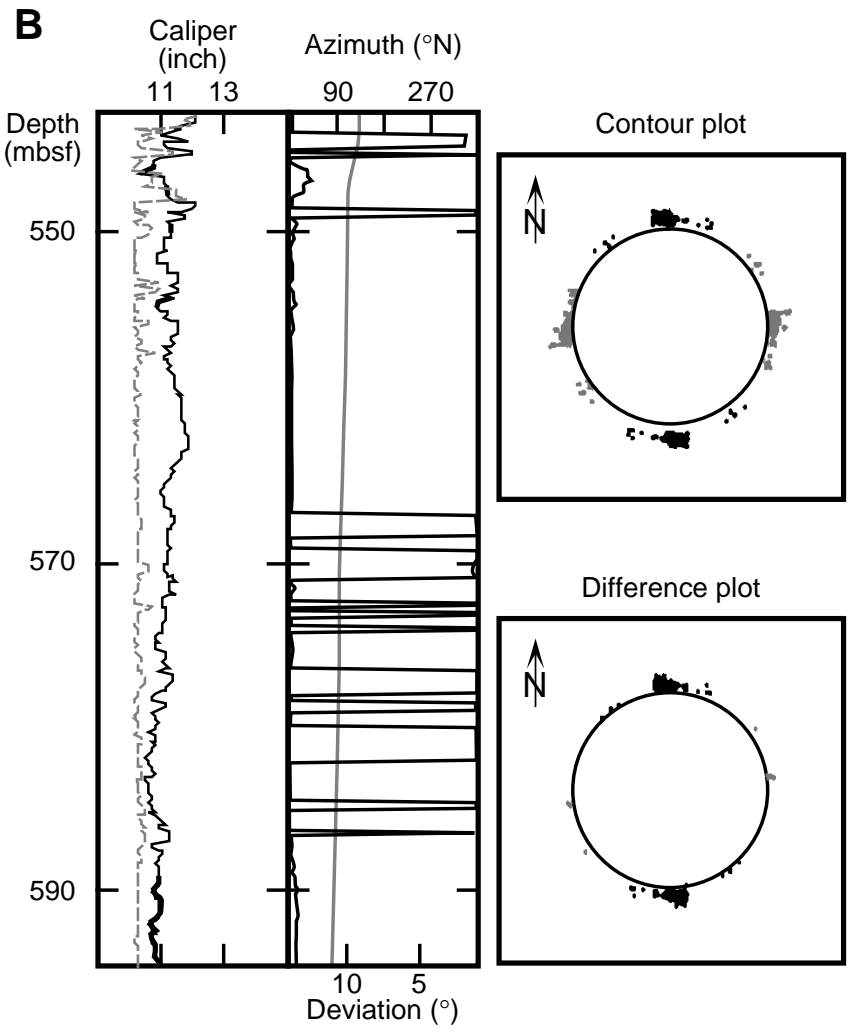

Figure 5. Four-arm caliper results from Hole 959D. A. Selected interval from 545 to $923 \mathrm{mbsf}$. B. Selected interval from 546 to $593 \mathrm{mbsf}$. The contour and difference plots show the true bit size as a circle. The orientation and size of caliper readings are plotted in the contour plot. The orientation and value of the difference in caliper readings are plotted in the difference plot. This plot is used to eliminate the influence of washouts in the presentation of the breakouts. "Wrong values" occur in sections where the hole azimuth is subparallel to the Pad 1 azimuth and Pad 1 azimuth $+180^{\circ}$.

The hole deviation increases slowly from $5^{\circ}$ to $8^{\circ}$ down to 750 mbsf. Below this depth, the hole deviation increases more rapidly and is $13.5^{\circ}$ at $925 \mathrm{mbsf}$. The hole azimuth ranges from $340^{\circ}$ to $350^{\circ} \mathrm{N}$ in the logged interval, and similar values are generally recorded for the Pad 1 azimuth. Large variations in the Pad 1 values occur at washout sections (Fig. 3). The large washout from 865 to $885 \mathrm{mbsf}$ resulted in a $90^{\circ}$ rotation of the tool, such that $\mathrm{C} 2$ becomes the larger caliper, according to the caliper readings.

The difference between the Pad 1 and hole azimuths is less than $10^{\circ}$ in most of the logged interval (i.e., "wrong values"), and these sections are therefore excluded from the breakout analysis (Fig. 5A). This makes it difficult to find good breakout candidates (i.e., sections where one caliper increases while the other is constant and where the Pad 1 azimuth records rather constant values that are different from the hole azimuth). As a result, I only found five breakout candidates that fulfill all breakout criteria (Table 2). The clearest breakout candidate is measured from 548.1 to $589.0 \mathrm{mbsf}$, and it has an elongation azimuth of $0^{\circ} \mathrm{N}$ (Fig. 5B). There are three short intervals of "wrong values" from 548 to $590 \mathrm{mbsf}$, a total of $2.2 \mathrm{~m}$ in length. Two of the remaining four breakouts are less clear: (1) the breakout candidate
Table 2. Summary of borehole breakout candidates encountered in Hole 959D.

\begin{tabular}{crccc}
\hline $\begin{array}{c}\text { Depth } \\
(\mathrm{mbsf})\end{array}$ & \multicolumn{1}{c}{$\begin{array}{c}\text { Azimuth } \\
\left({ }^{\circ} \mathrm{N}\right)\end{array}$} & $\begin{array}{c}\text { Breakout angle Breakout depth Hole deviation } \\
\left({ }^{\circ}\right)\end{array}$ & & \\
& & & & \\
& & & & \\
\hline $589.0-548.1$ & 0 & 22 & 137 & 5.5 \\
$838.6-837.6$ & 140 & 21 & 158 & 10 \\
$875.9-874.1$ & 145 & 23 & 137 & 11.5 \\
$888.4-878.1$ & 17 & 39 & 147 & 12 \\
$900.3-890.0$ & 7 & 34 & 137 & 12.5 \\
\hline
\end{tabular}

Notes: The definition of breakout angle and breakout depth is shown in Figure 4. The radius of the bit size $=125 \mathrm{~mm}$.

from 878.1 to 888.4 mbsf contains three intervals of "wrong values," totaling $2.7 \mathrm{~m}$ in length. The smaller caliper is larger than bit size, but because it varies less than the larger caliper, it still fulfills the breakout criteria (listed above) and suggests an azimuth of $17^{\circ} \mathrm{N}$; (2) the deepest breakout candidate (890.0-900.0 mbsf) has a similar appearance as the one from 878.1 to $888.4 \mathrm{mbsf}$. However, $4.1 \mathrm{~m}$ of this in- 
terval consists of "wrong values," suggesting that it is more affected by drill-pipe wear. If the sections with "wrong values" are included, the total length of the five breakout candidates is $64.3 \mathrm{~m}$ and the weighted mean azimuth is $3^{\circ} \pm 10^{\circ} \mathrm{N}$.

\section{FMS Sensor of FMS Tool}

A large number of small-scale and highly conductive fractures are detected parallel to the borehole axis in Hole 959D (Fig. 6). These fractures are not present in the cores. Their individual lengths range from 0.04 to $9.57 \mathrm{~m}$, and the average and median lengths are 0.39 and $0.26 \mathrm{~m}$, respectively. The majority of the fractures are parallel to the borehole axis, and typical examples are shown in Figure 7. Only three observations of the en echelon "chevron" pattern of wall fractures are observed at 577.6, 593.6 and 597.7 mbsf, respectively. Because of only a moderate tool rotation, the measurements have been mainly restricted to four directions that roughly lie in the point of the compass (i.e., $57-94^{\circ} \mathrm{N}, 147-196^{\circ} \mathrm{N}, 239-261^{\circ} \mathrm{N}$, and $330-6^{\circ} \mathrm{N}$ ). Nevertheless, a clear pattern in both the downhole and angular distribution of fractures is observed. There is a distinct change in the downhole distribution of fractures at about 750 mbsf (Fig. 6). The majority (84\%) of all fractures is detected above this depth. Below $750 \mathrm{mbsf}$, fractures are only measured in short sections, covering a total length of less than $30 \mathrm{~m}$ of the borehole. A bimodal angular distribution is observed in the fractures that are parallel to the borehole axis (Fig. 8).

In order to simplify the further presentation and increase the clarity, the fractures are grouped with respect to their azimuth (Table 3). In addition, the appearance of individual fractures varies, both with respect to the clarity (i.e., conductivity contrast between the fracture and the surrounding sediment) and the width of the fractures. Each fracture has therefore been classified qualitatively regarding those

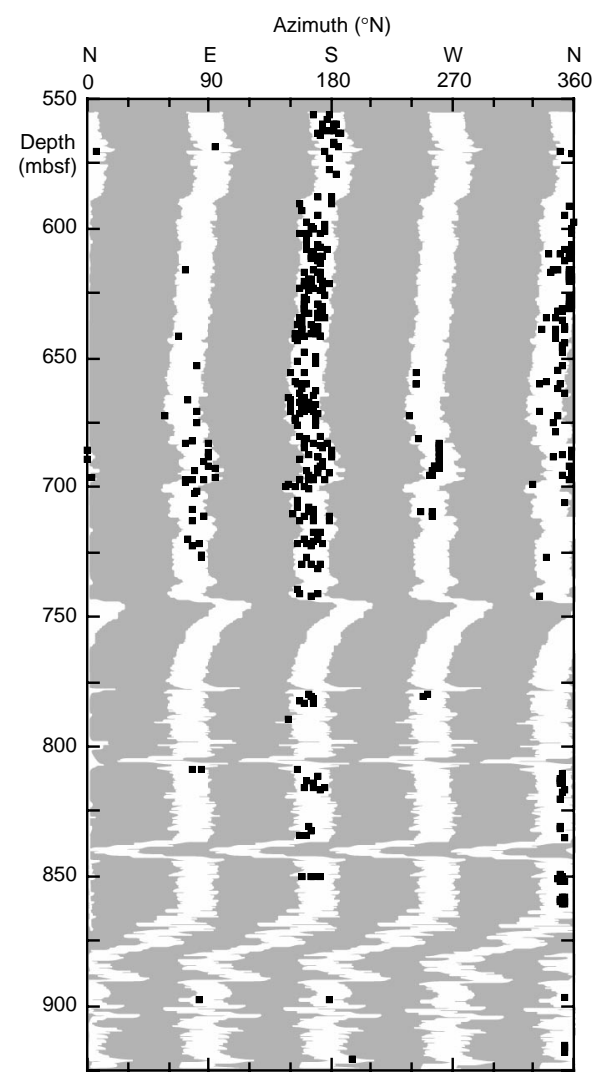

Figure 6. Distribution of small-scale vertical fractures in Hole 959D. The shaded area shows parts of the borehole wall that are outside the measured section. Note that the size of the data points is greater than the length of the fracture. two characteristics. I used three types of description for clarity of the fracture (i.e., clear, partially unclear, and unclear), and for their width (i.e., wide, medium, and narrow). This classification is purely based on visual comparison of the data and examples of fractures classification are included in the caption of Figure 7. The primary purpose of the classification is to determine if there is any systematic variation in the fracture's appearance, such as the depth and angular distribution of the various types of fractures. The downhole distribution of wide, medium, and narrow fractures is shown in Figure 9. Figure 10 depicts the distribution of clear, partially unclear, and unclear fractures.

Most fractures (60\% of 418 fractures) have azimuths within the range from $147^{\circ}$ to $196^{\circ} \mathrm{N}$ (Group IIA). They have a weighted mean azimuth of $166^{\circ} \pm 9^{\circ} \mathrm{N}$. The fractures are generally measured in abundance above $750 \mathrm{mbsf}$ and between 775 and $850 \mathrm{mbsf}$. Most of them $(91 \%)$ have medium width (Fig. 9). Narrow fractures occur mainly in four sections: in porcellanite at $\sim 620 \mathrm{mbsf}$, in two clay- and micriterich intervals at 680 and $780 \mathrm{mbsf}$, and in black claystone at 830 mbsf. Two wide fractures are measured at $\sim 680$ mbsf. Group IIA consists mostly of clear fractures ( $82 \%$ of 249 fractures); these are most abundant above 750 mbsf (Fig. 10). Almost 15\% of the fractures are classified as partially unclear. They occur at most depths, except for the interval between 630 and 680 mbsf. A total of nine unclear fractures was detected, and most of them occur between 660 and 750 mbsf.

A total of 108 fractures (26\%) is sorted into Group IIB, with a weighted mean azimuth of $352^{\circ} \pm 5^{\circ} \mathrm{N}$. The fractures are mainly distributed within two intervals, from 570 to $700 \mathrm{mbsf}$ and from 815 to 865 mbsf. Group IIB contains a slightly lower percentage of normalwide fractures (81\%) compared to Group IIA, but they are evenly distributed over the two fracture intervals (Fig. 9). The five wide fractures in this group are located above $700 \mathrm{mbsf}$. The narrow fractures $(15 \%)$ are mostly restricted to two intervals, from 620 to $660 \mathrm{mbsf}$ and from 810 to $860 \mathrm{mbsf}$. The percentage of clear, partially clear and unclear fractures in Group IIB is similar to that in Group IIA (Fig. 10). The clear fractures constitute $74 \%$ of all fractures, and they occur in both of the two fracture intervals. The partially unclear fractures $(22 \%)$ have a more distinct depth distribution; most of them are restricted to the intervals from 590 to $675 \mathrm{mbsf}$ and 850 to $870 \mathrm{mbsf}$.

The angle between the weighted mean azimuth of Groups IIA and IIB is $174^{\circ}$, which is slightly less than the theoretical value for planar features $\left(180^{\circ}\right)$. However, many of the fractures in Group IIB are measured near the edge of the FMS sensor (Fig. 6), suggesting that more fractures exist outside the measured interval.

Group I consists of the remaining $15 \%$ of the fractures, and most of them are measured in a restricted depth interval from 650 to 725 mbsf (Figs. 9, 10). Fractures in Group IA have an azimuth range from $57^{\circ}$ to $94^{\circ} \mathrm{N}$ and they mostly occur in the clay- and micrite-rich section between 650 and 725 mbsf. The weighted mean azimuth for these fractures is $81^{\circ} \pm 9^{\circ} \mathrm{N}$. Fractures in Group IB occur over a shorter depth interval, from 650 to 710 mbsf. These fractures have an azimuth range from $239^{\circ}$ to $261^{\circ} \mathrm{N}$ and a weighted mean azimuth of $253^{\circ} \pm 7^{\circ} \mathrm{N}$. About $70 \%$ of the fractures in both groups have a medium width (Fig. 9). However, whereas the remaining 10 fractures in Group IA are classified as wide, those in Group IB are, with two exceptions, classified as narrow. Narrow fractures were not measured in Group IA. The majority ( $72 \%$ of 25 fractures) of the fractures in Group IB are clear (Fig. 10). The corresponding number for Group IA is $58 \%$ (of 36 fractures). The angle between the mean azimuth of Groups IA and IB is $172^{\circ}$, which is similar to that of Group II. However, most of the fractures in Group I were measured in the center of the FMS sensors (Fig. 6). 

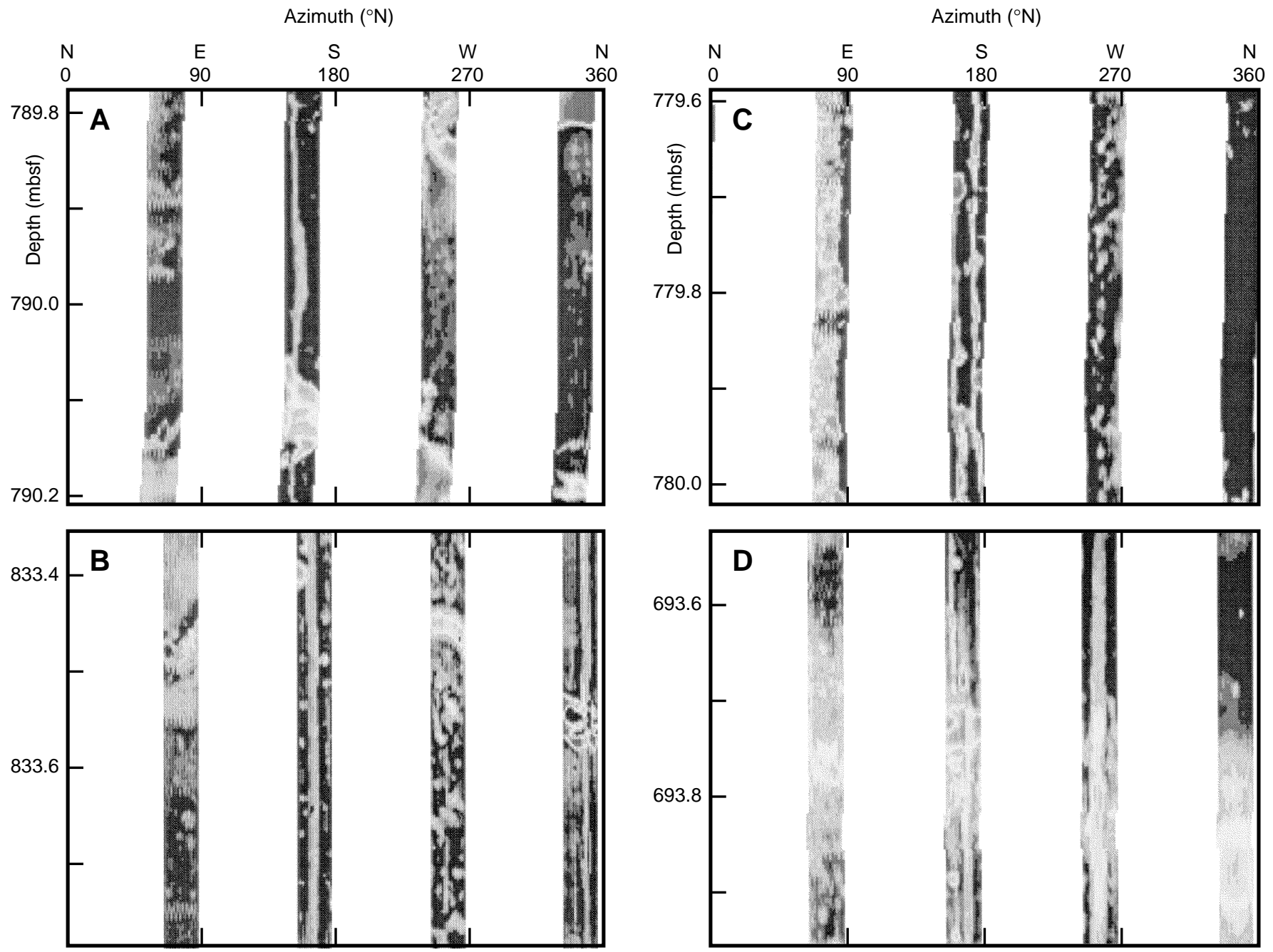

Figure 7. Examples of FMS images encountered in Hole 959D. A. Most often, only one fracture was detected. The fracture is classified as clear and narrow. B. Opposing fractures were commonly observed. The fracture at $165^{\circ} \mathrm{N}$ is classified as partially unclear and medium wide, and the fracture at $350^{\circ} \mathrm{N}$ is classified as clear and narrow. C. Sometimes multiple (two to three) fractures were encountered on the same pad and depth interval. The fracture at $164^{\circ} \mathrm{N}$ is classified as partially unclear and narrow, and the fracture at $179^{\circ} \mathrm{N}$ is classified as clear and narrow. D. Fifteen percent of the fractures were detected in the east-west direction $\left(57^{\circ}-94^{\circ} \mathrm{N}\right.$ and $239^{\circ}-261^{\circ} \mathrm{N}$, respectively). The fracture at $255^{\circ} \mathrm{N}$ is classified as partially unclear and wide.

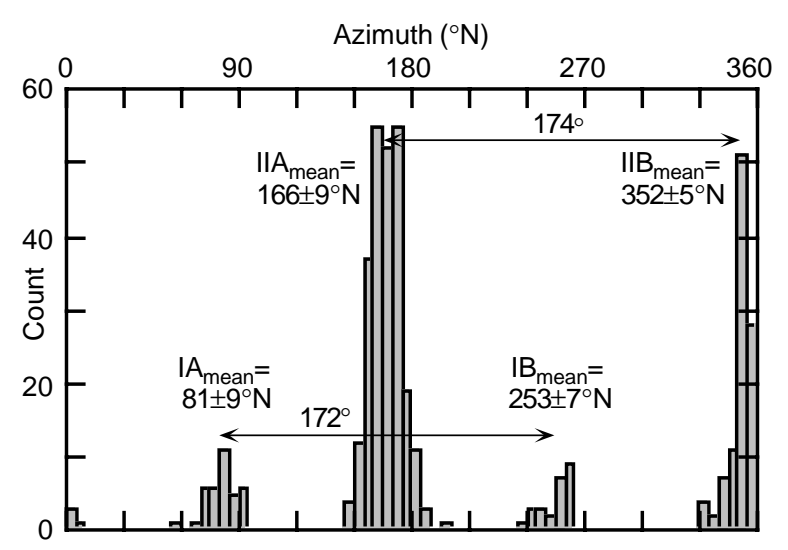

Table 3. Fracture groups.

\begin{tabular}{lcccc}
\hline Group & Group IA & Group IIA & Group IB & Group IIB \\
\hline Azimuth range $\left({ }^{\circ} \mathrm{N}\right)$ & $57-94$ & $147-261$ & $239-261$ & $330-6$ \\
Mean Azimuth \pm s.d. $\left({ }^{\circ} \mathrm{N}\right)$ & $81 \pm 9$ & $166 \pm 9$ & $253 \pm 7$ & $352 \pm 5$ \\
Number of fractures & 36 & 249 & 25 & 108 \\
Length of fractures(m) & 14.48 & 92.50 & 8.23 & 46.80 \\
Width: & & & & \\
$\quad$ Wide (\%) & 28 & 1 & 8 & 5 \\
$\quad$ Medium (\%) & 72 & 91 & 68 & 81 \\
$\quad$ Narrow (\%) & 0 & 8 & 24 & 15 \\
Clarity: & & & & \\
$\quad$ Clear $(\%)$ & 58 & 82 & 72 & 74 \\
Partially unclear (\%) & 28 & 14 & 28 & 22 \\
$\quad$ Unclear (\%) & 14 & 4 & 0 & 4 \\
\hline
\end{tabular}

Note: s.d. $=$ standard deviation

Figure 8. Histogram of angular distribution of vertical fractures in Hole 959D. Mean azimuth and the standard deviation are shown for each group, together with the angle between the mean azimuths of opposing fracture groups. 
Figure 9. Distribution of small-scale vertical fractures in Hole 959D ranked with respect to width. The shaded area shows parts of the borehole wall that are outside the measured section.
Figure 10. Distribution of small-scale vertical fractures in Hole 959D ranked with respect to clarity. The shaded area shows parts of the borehole wall that are outside the measured section.
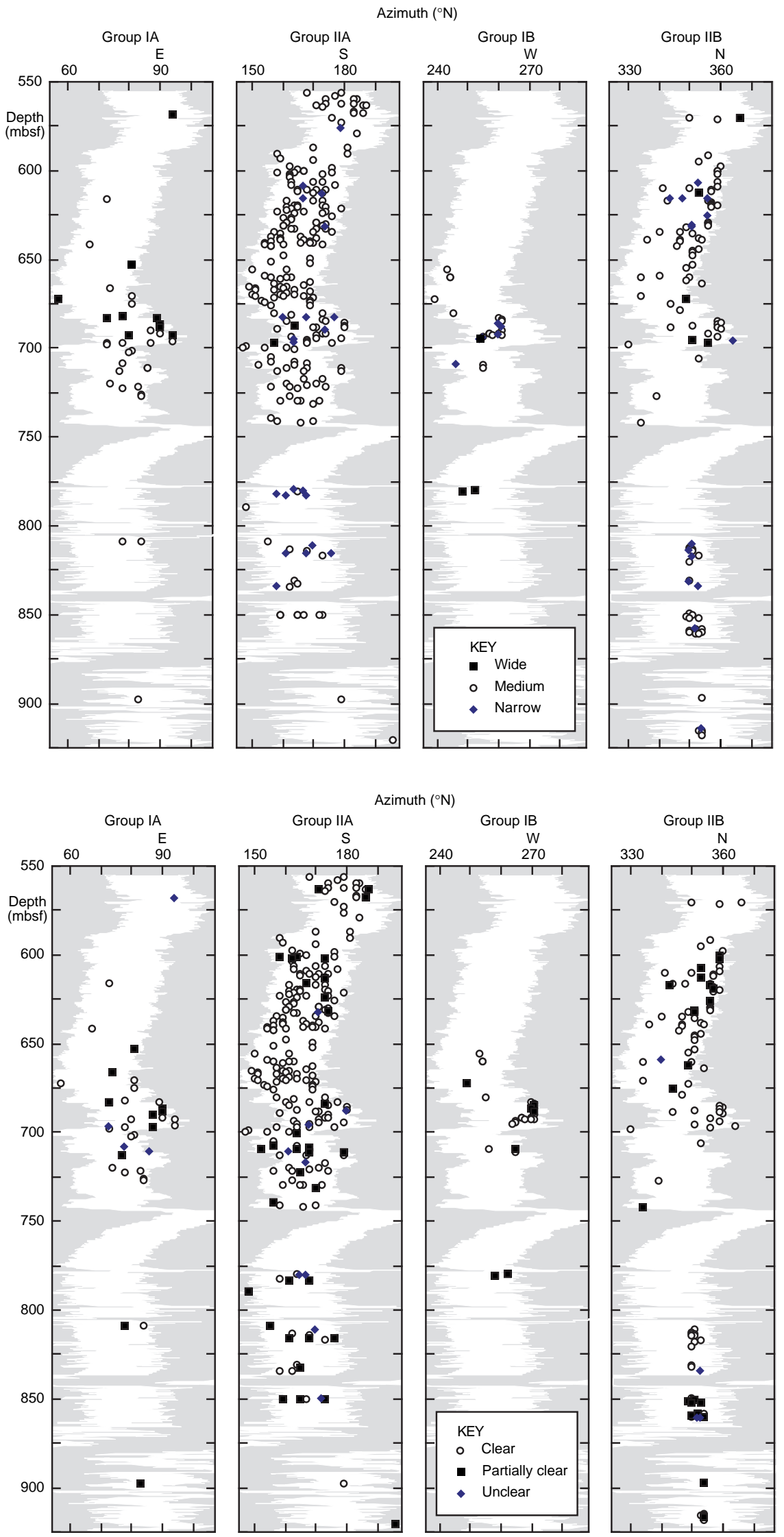


\section{DISCUSSION}

The azimuth and downhole distribution of elongation zones and vertical fractures have been presented above. An interpretation of the orientation of $S_{H}$ is made below, including a comparison between the downhole distribution of fractures with respect to the drilling results. The obtained mean $\mathrm{S}_{\mathrm{H}}$ orientation will be compared with stress orientations derived from earthquakes near the study area and the firstorder stress province. Their internal relationships will then be discussed with respect to potential sources for the observed stress orientations. Finally, possible contributions to the Site 959 objectives will be discussed.

\section{Interpretation of In Situ Stress in Hole 959D}

\section{Orientation of $S_{H}$}

The results of the four-arm caliper analyses suggest that large parts of Hole 959D contain mechanically induced borehole elongations. Only five sections are found that fulfill the breakout criteria. They indicate an east-west orientation of $\mathrm{S}_{\mathrm{H}}$. However, the breakout candidates either contain intervals with "wrong values" or are shallow and/or short; therefore, if this study had been based solely on four-arm caliper data, one would have concluded that the hole elongation was mostly mechanically induced by drill-pipe wear and no conclusions of the orientation of $\mathrm{S}_{\mathrm{H}}$ could have been made.

The results from the FMS-sensor analysis show that many smallscale vertical fractures exist in borehole wall. This implies that Hole 959D has been elongated by both mechanical wear and overstressing. In total, 418 vertical fractures with a weighted mean azimuth of $168^{\circ}$ $\pm 24^{\circ} \mathrm{N}$ and a total length of $162.14 \mathrm{~m}$ were measured. The fracture distribution is bimodal (Fig. 8): $85 \%$ of the fractures have a mean azimuth of $168^{\circ} \pm 8^{\circ} \mathrm{N}$ (Group II), whereas the remaining $15 \%$ of the have a mean azimuth of $78^{\circ} \pm 9^{\circ} \mathrm{N}$ (Group I). Except for three en echelon fractures, all fractures are oriented parallel with the borehole axis, suggesting that one principal stress is oriented parallel to the borehole axis (Péska and Zoback, 1995). The calculation of the overburden pressure suggests that the magnitude of $S_{\mathrm{V}}$ ranges from at least 9 to $16 \mathrm{MPa}$ over the study interval.

The question is, then, what kinds of fractures were encountered? Are the fractures in Group II parts of borehole breakouts and indicative of the $S_{h}$ orientation, or are they tensile wall fractures that are parallel to the orientation of $S_{H}$ ? A borehole breakout is expected to generate a wide, ragged-shaped vertical image that ranges over a meter to several tens of meters (Shamir and Zoback, 1992; Brudy et al., 1997). A tensile wall fracture on the other hand, is expected to be a small-scale image of small width and short length (decimeter to meter scale) (Brudy and Zoback, unpubl. data). The examination of the individual fractures in Group II shows that they are small-scale features (Figs. 7A, B). In some intervals, two to three fractures occur within the same depth interval and pad (Fig. 7C). These could be interpreted as being part of a borehole breakout. However, they have the same orientation as the single fractures and they occur within the same depth interval. Brudy and Zoback (unpubl. data) and Brudy et al. (1997) mention that one single tensile wall fracture is formed on each side of the borehole $180^{\circ}$ apart. However, others (Hillis and Williams, 1992; Apel et al., 1993) have indicated that more than one tensile wall fracture can simultaneously appear on each side of the borehole (cf. Fig. 4). Based on the above, the fractures within Group II are concluded to be tensile wall fractures that show the orientation of $\mathrm{S}_{\mathrm{H}}$, and hence that they are not parts of borehole breakouts.

Fractures in Group I are mainly restricted to the section from 650 to $725 \mathrm{mbsf}$, and they have an orthogonal orientation with respect to those in Group II (i.e., the tensile wall fractures; Fig. 7D). Their orientation with respect to the tensile wall fractures suggests that they are small borehole breakouts. Following the argumentation above, the fractures in Group I should generally be wider and longer than those in Group II. However, the classification regarding the width of individual fractures shows that this is not always the case (Fig. 9). Only $20 \%$ of all fractures in Group I are wide fractures, whereas $70 \%$ of the fractures have a medium width. The average length of the wide fractures is $0.66 \mathrm{~m}$, which is somewhat longer than those of medium width $(0.28 \mathrm{~m})$. The classification about the clarity shows that $36 \%$ of the fractures in Group I are partially unclear or unclear (Fig. 10). In comparison, only $2 \%$ of the fractures in Group II are wide, whereas $20 \%$ of all fractures in Group II are partially unclear or unclear. Thus, the conclusion from the above is that it is not possible to define unequivocally the fractures in Group I as being borehole breakouts and show the orientation of $S_{h}$. However, their orientation and the slightly higher percentage of wide and partially unclear or unclear fractures indicate that they are very weak borehole breakouts.

In summary, Hole 959D is much affected by drill-pipe wear as a result of the large hole deviation. The detailed analysis of the FMS sensor suggests a $168^{\circ} \pm 8^{\circ} \mathrm{N}$ weighted mean $S_{H}$ orientation. The low standard deviation $\left( \pm 8^{\circ}\right)$ indicates that this $S_{H}$ orientation is uniform throughout the investigated interval. The data further indicates that very weak borehole breakouts, with a weighted mean $S_{h}$ orientation of $78^{\circ} \pm 9^{\circ} \mathrm{N}$, may occur in the interval from 650 to $725 \mathrm{mbsf}$.

\section{Downhole Variation in Fracture Distribution}

The majority of tensile wall fractures were detected in seismic Unit D and lithologic Subunit IIC (Fig. 3). Relatively often, tensile wall fractures were only detected along one pad (Figs. 6, 7A, 8), and not on both of the opposing pads as suggested by Brudy and Zoback (unpubl. data) and Brudy et al. (1997). Because the fracture distribution is less in the direction of hole azimuth, it could be interpreted that the drill pipe has ground away the fractures on this side. This observation further supports the interpretation that the fractures are tensile wall fractures. By definition, tensile wall fractures are shallow features that may easily be ground away by the drill pipe.

Figure 3 shows that porosity, density and $P$-wave velocity have uniform downhole distribution in seismic Unit D and in lithologic Subunit IIC, down to about $750 \mathrm{mbsf}$. A shift to denser and more compacted sediments (low porosity) with higher $P$-wave velocities occurs from about $750 \mathrm{mbsf}$. The higher velocity and density, and lower porosity values imply that the strength of the sediment increases in seismic Unit C and lithologic Unit III. An increase of the sediment strength implies a corresponding increase in the Young's modulus, which, according to Equation 2, results in an increase in the thermally induced stress. Nevertheless, the abrupt end in the occurrence of tensile wall fractures is attributed to the change in the physical properties of the sediment. Apparently, the tensile strength of the sedimentary rock below $750 \mathrm{mbsf}$ is generally greater than the sum of thermal and tectonic stresses.

\section{Stress Fields near the Côte d'Ivoire- Ghana Marginal Ridge}

Zoback (1992) identified a region in western and north central Africa of compressional tectonism with an approximately east-west $S_{H}$ orientation (Fig. 11A). Based on the plate tectonic setting of Africa (surrounded by mid-ocean ridges and a continental collision in the north), Zoback et al. (1989) suggested that Africa is affected by a midcontinental compressional stress field. The definition of this firstorder stress province was based on fault-plane solutions of large earthquakes in West Africa between 1939 and 1983 (Suleiman et al., 1993), CMT solutions, and borehole breakout data from Sudan (Bosworth et al., 1992). The new data from Suleiman et al. (1993) (Table 1) indicate strike-slip and thrust-fault regimes, which is in agreement with the observations of Zoback (1992). However, neither the earthquake data in the vicinity of the Leg 159 area nor the $168^{\circ} \pm 8^{\circ} \mathrm{N}$ ori- 

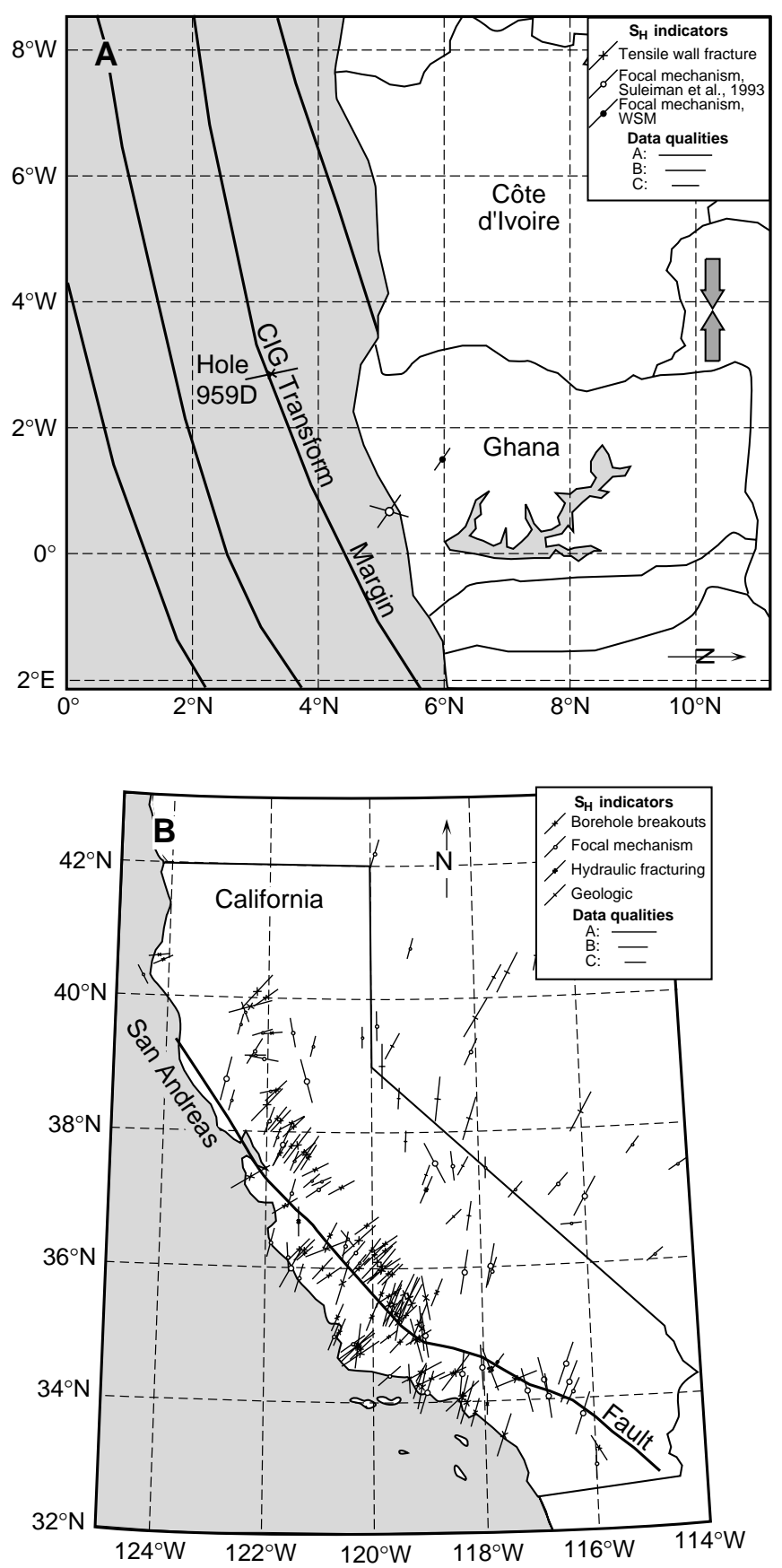

Figure 11. A. Orientation of maximum horizontal stress along the Côte d'Ivoire-Ghana Transform Margin. The orientation of the first-order stress field of western and north central Africa is shown by the gray arrows. B. Orientation of maximum horizontal stress along the San Andreas fault. The symbol associated with each data point indicates the type of stress indicator. Focal mechanism data come from two different sources: data from the World Stress Map are shown as solid circles and data from Suleiman et al. (1993) are shown in open circles. Stress data from other stress-measuring methods come from the World Stress Map. Data qualities of stress measurements are assigned according to the World Stress Map quality ranking scheme (Zoback, 1992), and the length of the bar attached to each data point is a measure of its quality (A, B, or C). The new data point from Hole 959D is included. Because no ranking scheme for tensile wall fractures have been constructed as yet, the length of the bar is not ranked with respect to its quality. entation of $S_{H}$ in Hole 959D agrees with the suggested east-west $S_{H}$ orientation of the first-order stress province.

Five focal mechanisms from earthquakes have been reported close to the Leg 159 area. In Ghana, the three focal mechanisms indicate a strike-slip faulting stress regime with west-northwest-eastsoutheast $\left(305^{\circ}\right.$ and $\left.125^{\circ} \mathrm{N}\right)$ and north-northeast-south-southwest $\left(16^{\circ} \mathrm{N}\right)$ orientations of $\mathrm{S}_{\mathrm{H}}$ (Table 1; Fig. 11A). To the south, the two focal mechanisms demonstrate a thrust faulting stress regime with a north-south orientation of $\mathrm{S}_{\mathrm{H}}$. These two focal mechanisms are thought to have been derived from the same earthquake.

The above shows that the stress orientations obtained in Hole 959D and from nearby earthquakes are not in agreement with the east-west orientation of the first-order stress field of western and central north Africa. Sediment loading, lateral variation in crustal thickness and density, and lateral strength contrasts are potential sources for second-order stress patterns at continental margins (Zoback, 1992), and their influence on the stress field near the CIG Transform Margin is discussed below.

\section{Sediment Loading}

Sediment loading is a major source of stress at passive continental margins, where the sediment thickness often is more than $10 \mathrm{~km}$ (e.g., Cloetingh et al., 1982). Stein et al. (1989) suggest that the state of stress on the continental shelves is dominated by sediment loading rather than by other stress sources that are active there (i.e., platedriving forces, lateral density contrasts between oceanic and continental crust, and glacial rebound). They suggest that sediment loading will generate $S_{\mathrm{H}}$ orientations parallel to the continental slope.

Hole 959D is situated on continental crust, and almost has an orthogonal $S_{H}$ orientation with respect to the strike of the CIGMR. The CIGMR has a slight arcuate shape in the Leg 159 area, but a general east-northeast-west-northwest strike (about $70^{\circ} \mathrm{N}$; Fig. 2A). Further to the east, the strike of the CIG Transform Margin changes to about $65^{\circ} \mathrm{N}$. The three fault-plane solutions from Ghana indicate westnorthwest-east-southeast and north-northeast-south-southwest $S_{H}$ orientations, and hence not parallel to the east-northeast-west-southwest strike of the CIG Transform Margin outside Ghana. The total sediment thickness in the Site 959 area is about $3000 \mathrm{~m}$, which is much less than that discussed by Cloetingh et al. (1982). The above suggests that the sediment loading is not an important source of stress in the CIGMR and Ghana region.

\section{Lateral Variation in Crustal Thickness and Density}

Bott and Dean (1972) suggest that the lateral variation in crustal thickness and density across continental margins can induce extensional stress (30-40 MPa) perpendicular to the strike of the margin on the continental side (and smaller compressional stress on the oceanic side). Assumpçao (1992) reported that four earthquakes and borehole breakout data from one well in Northeastern Brazil have parallel $S_{H}$ orientations with respect to the northern continental margin (Fig. 1). He interpreted that the stress field in this area is influenced by the lateral variation in crustal thickness and density, as well as the ridge-push from the Mid-Atlantic Ridge.

Figure $2 \mathrm{~B}$ shows the topography of the CIGMR. The ridge has a positive free-air gravity anomaly, whereas the continent/ocean boundary has a strong negative anomaly (Pontoise et al., 1990). The difference between the maximum and minimum gravity is in the order of $100 \mathrm{mGal}$. Nevertheless, the $\mathrm{S}_{\mathrm{H}}$ orientation in Hole 959D is almost perpendicular to the strike of the CIGMR. Moreover, from the east-northeast-west-southwest strike of the continental margin off Ghana, one would expect that the $S_{H}$ orientations from the earthquakes in this region would have roughly west-southwest-east-northeast trends, instead of the recorded west-northwest-east-southeast and north-northeast-south-southwest $S_{H}$ orientations. Consequently, 
as either the $\mathrm{S}_{\mathrm{H}}$ orientations in Hole 959D or those from focal mechanisms in Ghana are parallel to the strike of the continental margin, I conclude that the stress field there is not dominated by the lateral variation in crustal thickness and density.

Figure 2B shows that the topography of the CIGMR (Fig. 2B) must result in stress amplification of in situ stress in the direction that is perpendicular to the strike of the ridge, at least over the $3000-\mathrm{m}$ long depth interval over which the CIGMR towers above the Gulf of Guinea abyssal plain. This indicates that although the magnitude of compressional stress perpendicular to the ridge decreases as the result of the lateral variation in crustal thickness, they become amplified as the result of the local topography.

\section{Lateral Strength Contrasts}

Zoback et al. (1987) suggested a new model of how the orientation of in situ stress changes across a strike-slip fault as the result of lateral variation in strength. In their model, the strength contrast is presumed to be the effect of a fault of low frictional shear strength embedded in a frictionally strong crust; far from the fault, shear stresses are high and contained by the frictional strength of the crust, whereas shear stresses on planes parallel to the fault are quite low. Hence, the principal stresses become re-oriented so as to minimize shear stress on planes parallel to the fault and the fault becomes a principal stress plane. According to this model, the orientation of $S_{H}$ becomes nearly orthogonal to the fault if the regional compression is at an angle to the fault of more than $45^{\circ}$. However, if the angle is less than $45^{\circ}$, the orientation of $S_{H}$ becomes almost parallel to the strike of the fault.

The model by Zoback et al. (1987) was originally formed to explain the variation of in situ stress across the San Andreas fault in California. Various types of in situ stress measurements and other geological and geophysical indicators (Fig. 11B) demonstrate that the $\mathrm{S}_{\mathrm{H}}$ orientations in a 100 - to $125-\mathrm{km}$ wide zone on either side of the San Andreas fault are oriented almost perpendicular $\left(75^{\circ}-85^{\circ}\right)$ to the strike of the fault (Mount and Suppe, 1987; Zoback et al., 1987; Zoback, 1991; Mount and Suppe, 1992). The data show that there is much strike-slip and normal faulting to the east of the fault, whereas the deformation is wholly compressional and dominated by folding, strike-slipping, and reverse faulting west of the San Andreas fault. Classical faulting theory cannot explain compression at such a high angle to a strike-slip fault because the Pacific and North American plate motions are slightly convergent. Thus, they suggest that because of the presumed low shear strength in the San Andreas Fault, interpreted independently from heat-flow data (e.g., Lachenbruch and Sass, 1980), the regional stress fields have rotated by approximately $50^{\circ}$.

The angle between the strike of the CIG Transform Margin and the $S_{\mathrm{H}}$ orientations from the three focal mechanisms in Ghana is about $50^{\circ}$ and $65^{\circ}$ to the east-northeast-west-southwest strike of the CIG Transform Margin (Fig. 11B). The angle between the mean $S_{H}$ orientation of $168^{\circ} \mathrm{N}$ in Hole 959D and the strike of the CIGMR $\left(\approx 70^{\circ} \mathrm{N}\right)$ is almost perpendicular $\left(\approx 88^{\circ}\right)$. Thus, these observations demonstrate $S_{H}$ orientations that suggest that the first-order stress field of western and north central Africa does not exist near the CIG Transform Margin. It is hypothesized that lateral variation in strength in the CIG Transform Margin is the source of the observed deviations. One focal mechanism has an oblique $\left(49^{\circ}\right)$, and the two other focal mechanisms in Ghana have steeper angles $\left(65^{\circ}\right)$ with respect to the strike of the CIG Transform Margin. These oblique angles could be indicative in that these earthquakes are situated close to the border of the zone where re-orientation of $\mathrm{S}_{\mathrm{H}}$ occurs. If this assumption is correct, it indicates that the zone of re-orientation is about $100 \mathrm{~km}$ wide. This is of similar size to the zone of re-orientation near the San Andreas fault. Only four measurements do not allow unquestionable conclusions to be drawn about the state of stress; nevertheless, the stress observation closest to the transform margin has a near-perpen- dicular orientation with respect to the strike of the CIGMR, and the three stress observations at larger distances have angles to the strike of the CIG Transform Margin of more than $45^{\circ}$. This suggests that the CIG Transform Margin is a weak fault that generates a second-order stress province. The stress orientations of the focal mechanisms suggest that the weak fault affects a $100-\mathrm{km}$-wide zone to the north of the margin in which the principal stresses become re-oriented.

\section{Speculations on $S_{H}$ Orientation and Source of Stress in the CIGMR}

Above, I have presented three potential sources that can generate second-order stress patterns along continental margins; sediment loading, lateral variation in crustal thickness and density, and lateral variation in strength. Although only four measurements does not allow for certain conclusions to be drawn about a second-order stress province and its sources, I have argued that the lateral variation in strength within the CIG Transform Margin is the most probable source for the observed data. This implies that the CIG Transform Margin acts as a weak fault, at least in the CIGMR and Ghana area. However, because the argumentation is based on my interpretation that the $\mathrm{S}_{\mathrm{H}}$ orientation is $168^{\circ} \mathrm{N}$ in Hole $959 \mathrm{D}$, and because this interpretation was not totally unequivocal, I will briefly discuss how an $S_{H}$ orientation of $78^{\circ} \mathrm{N}$ in Hole 959D compares with the two former potential stress sources.

According to Stein et al. (1989), sediment loading will generate $\mathrm{S}_{\mathrm{H}}$ orientations parallel to the continental slope, and Bott and Dean (1972) suggest that lateral variation in crustal thickness and density also result in $\mathrm{S}_{\mathrm{H}}$ orientations that are parallel to the continental margin. An $S_{H}$ orientation of $78^{\circ} \mathrm{N}$ in Hole 959D is subparallel to the $70^{\circ} \mathrm{N}$ strike of the CIGMR, which would suggest that these two sources influence the stress field. However, as pointed out above, the $\mathrm{S}_{\mathrm{H}}$ orientations of the three focal mechanisms are not parallel to the transform margin off Ghana. The angular differences between the east-northeast-west-southwest striking continental margin and the three focal mechanisms are about $50^{\circ}$ and $65^{\circ}$ (Table 1 and Fig. 11A). This observation supports my interpretation of the $S_{H}$ orientation in Hole 959D - that the CIG Transform Margin acts as a weak fault, and that lateral variation in the strength controls the stress field near the CIG Transform Margin.

\section{Contributions to the Site 959 Objectives}

The main contribution from the drilling objectives of Site 959 is the hypothesis that the CIG Transform Margin is a weak fault, at least in the region of the CIGMR. This implies that it has a low shear strength and is capable of sustaining only low shear stresses. As a result, the principal stresses become re-oriented near the fault, and the fault becomes a principal stress plane. These characteristics of the fault must have had great influence on the evolution of the CIG Transform Margin; for example, they may have influenced the type of deformation in sediments and rocks on both sides of the margin, and they may have simplified vertical and horizontal slip along the fault. However, because only a few stress data are available in the region at this stage, it is not possible to further verify the hypothesis.

\section{CONCLUSIONS}

The orientation of horizontal stress in Hole 959D has been derived from the FMS tool. My findings about the $S_{H}$ orientation in Hole 959D and the downhole distribution of tensile wall fractures are as follows:

1. The four-arm caliper analyses could not distinguish between mechanically and stress-induced borehole elongations because of similar values of the hole azimuth and the Pad 1 azimuth. 
2. The FMS-sensor data show that one of the principal stresses is parallel to the borehole axis. The calculation of the overburden pressure suggests that the magnitude of $\mathrm{S}_{\mathrm{V}}$ ranges at least from 9 to $16 \mathrm{MPa}$ in the studied interval.

3. The analysis of the FMS-sensor data suggests that tensile wall fractures occur in the borehole wall, and that they have a $168^{\circ}$ $\pm 8^{\circ} \mathrm{N}$ weighted mean $S_{H}$ orientation. The low standard deviation $\left( \pm 8^{\circ}\right)$ indicates that this $S_{H}$ orientation is uniform throughout the investigated interval. The data further indicates that very weak borehole breakouts, with a weighted mean $\mathrm{S}_{\mathrm{h}}$ orientation of $78^{\circ} \pm 9^{\circ} \mathrm{N}$, may occur in the interval from 650 to 725 mbsf.

4. There is a distinct change in the downhole distribution of tensile wall fractures. The depth of change coincides with a transition from weaker to stronger sediments at about $750 \mathrm{mbsf}$. Apparently, the strength of the sedimentary rock below 750 mbsf is generally greater than the sum of thermal and tectonic stresses.

The obtained $S_{H}$ orientation in Hole 959D has been compared with the orientation of the first-order stress field of western and north central Africa and the orientation of focal mechanisms in Ghana. My findings about the $S_{H}$ orientation in Hole 959D, with respect to the regional stress field and potential stress sources, are as follows:

1. The $S_{H}$ orientation in Hole 959D is almost perpendicular to the east-west $S_{H}$ orientation of the first-order stress province of western and north central Africa. Moreover, the $S_{H}$ orientations of the three focal mechanisms in Ghana have an angle of more than $45^{\circ}$ with respect to the strike of the CIG Transform Margin.

2. The available stress data suggests that $S_{H}$ becomes re-oriented in a 100-km-wide zone to the north of the CIG Transform Margin and that the CIG Transform Margin is a weak fault. Furthermore, the data suggests that sediment loading and lateral variation in crustal thickness and density may only have a minor influence on the stress field in this area.

\section{ACKNOWLEDGMENTS}

The borehole analyzing programs "Caliper 1.0 für Windows" and "FMSImage $2.1 \beta$ " are provided by the Geophysikalisches Institut at the University of Karlsruhe, Germany, and I would like to thank Birgit Müller and Martin Brudy for their assistance with these programs. The manuscript benefited from the reviews I received from Birgit Müller and Martin Brudy (University of Karlsruhe), David Moos (Stanford University), and Ove Stephansson (Royal Institute of Technology). Much appreciation is due Francisco Gomez (Cornell University) who generated the stress map on Figure 1 and who proofread the English of the final version of the manuscript. Graham Brew (Cornell University) is acknowledged for proofreading an earlier version of the English of the manuscript. This work has been supported by grants G-GU 03447-355 and G-GU 03447-242 from the Swedish Natural Science Research Council.

\section{REFERENCES}

Apel, R., Zoback, M.D., and Fuchs, K., 1993. Drilling-induced tensile fractures in the KTB pilot hole. Log Analyst, 34:1-48.

Assumpçao, M., 1992. The regional intraplate stress field in South America. J. Geophys. Res., 97:11889-11903.

Basile, C., Mascle, J., Popoff, M., Bouillin, J.P., and Mascle, G., 1993. The Côte d'Ivoire-Ghana transform margin: a marginal ridge structure deduced from seismic data. Tectonophysics, 222:1-19.

Bell, J.S., and Gough, D.I., 1979. Northeast-southwest compressive stress in Alberta: evidence from oil wells. Earth Planet. Sci. Lett., 45:475-482.

Bosworth, W., Strecker, M.R., and Blisniuk, P.M., 1992. Integration of East African Paleostress and present-day stress data: implications for continental stress field dynamics. J. Geophys. Res., 97:11851-11865.
Bott, M.H.P., and Dean, D.S., 1972. Stress systems at young continental margins. Nature Phys. Sci., 235:23-25.

Brudy, M., and Zoback, M.D., 1993. Compressive and tensile failure of boreholes arbitrarily-inclined to principal stress axes: application to the KTB boreholes, Germany. Int. J. Rock. Mech. Min. Sci. \& Geomech. Abstr., 30:1035-1038.

Brudy, M., Zoback, M.D., Fuchs, K., Rummel, F., and Baumgärtner, J., 1997 Estimation of the complete stress tensor to $8 \mathrm{~km}$ depth in the KTB scientific drill holes: implications for crustal strength. J. Geophys. Res., 102: 18453-18475.

Cloetingh, S.A.P.L., Wortel, M.J.R., and Vlaar, N.J., 1982. Evolution of passive continental margins and initiation of subduction zones. Nature, 297:139-142.

Ekstrom, M.P., Dahan, C., Chen, M.-Y., Lloyd, P., and Rossi, D.J., 1987. Formation imaging with microelectrical scanning arrays. Log Analyst, 28:294-306.

Fuchs, K., and Clauss, B., 1987. Borehole breakout method for stress determination: theory and practice. Univ. of Karlsruhe, Germany.

Hillis, R.R., and Williams, A.F., 1992. Borehole breakouts and stress analysis in the Timor Sea. In Hurst, A., Griffiths, C.M., and Worthington, P.F. (Eds.),Geological Applications of Wireline Logs II. Geol. Soc. Spec. Publ. London, 65:157-168.

Isacks, B., Oliver, J., and Sykes, L.R., 1968. Seismology and the new global tectonics. J. Geophys. Res., 73:5855-5899.

Kirsch, G., 1898. Die Theorie der Elastizität und die Bedürfnisse der Festigkeitslehre. VDIM-Z, 42:797-807.

Lachenbruch, A.H., and Sass, J.H., 1980. Heat flow and energetics of the San Andreas fault zone. J. Geophys. Res, 85:6185-6223.

Mardia, K.V., 1972. Statistics of Directional Data: London (Academic Press).

Mascle, J., Lohmann, G.P., Clift, P.D., et al., 1996. Proc. ODP, Init. Repts., 159: College Station, TX (Ocean Drilling Program).

Mastin, L., 1988. Effect of borehole deviation on breakout orientations. $J$. Geophys. Res., 93:9187-9195.

Moos, D., and Zoback, M.D., 1990. Utilization of observations of well bore failure to constrain the orientation and magnitude of crustal stresses: application to continental, Deep Sea Drilling Project, and Ocean Drilling Program boreholes. J. Geophys. Res., 95:9305-9325.

Mount, V.S., and Suppe, J., 1987. State of stress near the San Andreas fault: implications for wrench tectonics. Geology, 15:525-538.

1992. Present-day stress orientations adjacent to active strike-slip faults: California and Sumatra. J. Geophys. Res., 97:11995-12013.

Péska, P., and Zoback, M.D., 1995. Compressive and tensile failure of inclined well bores and determination of in situ stress and rock strength. J. Geophys. Res., 100:12791-12811.

Pezard, P.A., Hiscott, R.N., Lovell, M.A., Collela, A., and Malinverno, A., 1992. Evolution of the Izu-Bonin intraoceanic forearc basin, western Pacific, from cores and FMS images. In Hurst, A., Griffiths, C.M., and Worthington, P.F. (Eds.), Geological Applications of Wireline Logs II. Geol. Soc. Spec. Publ. London, 65:43-69.

Plumb, R.A., and Hickman, S.H., 1985. Stress-induced borehole elongation: a comparison between the four-arm dipmeter and the borehole televiewer in the Auburn geothermal well. J. Geophys. Res., 90:5513-5521.

Pontoise, B., Bonvalot, S., Mascle, J., and Basile, C., 1990. Structure crustale de la marge transformante de Côte d'Ivoire-Ghana deduite des observations de gravimétrie en mer. C. R. Acad. Sci. Ser. 2, 310:527-534.

Ritchie, R.H., and Sakakura, A.Y., 1956. Asymptotic expansions of solutions of the heat conduction equation in internally bounded cylindrical geometry. J. Appl. Phys., 27:1453-1459.

Shamir, G., and Zoback, M.D., 1992. Stress orientation profile to $3.5 \mathrm{~km}$ depth near the San Andreas Fault at Cajon Pass, California. J. Geophys. Res., 97:5059-5080.

Shipboard Scientific Party, 1996. Site 959. In Mascle, J., Lohmann, G.P., Clift, P.D., et al., Proc. ODP, Init. Repts., 159: College Station, TX (Ocean Drilling Program), 65-150.

Sipkin, S.A., 1986. Estimation of earthquake source parameters by the inversion of waveform data: global seismicity, 1981-1983. Bull. Seismol. Soc. Am., 76:1515-1541.

Stein, C.A., Cloetingh, S., and Wortel, R., 1989. SEASAT-derived gravity constraints on stress and deformation in the northeastern Indian Ocean. Geophys. Res. Lett., 16:823-826.

Stephens, G., and Voight, B., 1982. Hydraulic fracturing theory for conditions of thermal stress. Int. J. Rock Mech. Min. Sci., 19:279-284.

Suleiman, A.S., Doser, D.I., and Yarwood, D.R., 1993. Source parameters of earthquakes along the coastal margin of West Africa and comparisons 
with earthquakes in other coastal margin settings. Tectonophysics, 222:79-91.

Zoback, M.D., 1991. State of stress and crustal deformation along weak transform faults. Philos. Trans. R. Soc. London A, 337:141-150.

Zoback, M.D., Barton, C., Brudy, M., Chang, C., Moos, D., Péska, P., and Vernik, L., 1995. A review of some new methods for determining the in situ stress state from observations of borehole failure with application to borehole stability and enhanced production in the North Sea. In Fejerskov, M., and Myrvang, A.M., Rock Stresses in the North Sea, 13-14 February, 1995, Trondheim, Norway: Trondheim, Norway (SINTEF), 6-21.

Zoback, M.D., Moos, D., Mastin, L., and Anderson, R.N., 1985. Well bore breakouts and in situ stress. J. Geophys. Res., 90:5523-5530.

Zoback, M.D., Zoback, M.L., Mount, V.S., Suppe, J., Eaton, J.P., Healy, J.H., Oppenheimer, D.H., Reasenberg, P.A., Jones, L.M., Raleigh, C.B., Wong, I.G., Scotti, O., and Wentworth, C.M., 1987. New evidence on the state of stress of the San Andreas Fault. Science, 238:1105-1111.
Zoback, M.L., 1992. First- and second-order patterns of stress in the lithosphere: the world stress map project. J. Geophys. Res., 97:11703-11728.

Zoback, M.L., Zoback, M.D., Adams, J., Assumpção, M., Bell, S., Bergman, E.A., Blümling, P., Brereton, N.R., Denham, D., Ding, J., Fuchs, K., Gay, N., Gregersen, S., Gupta, H.K., Gvishiani, A., Jacob, K., Klein, R., Knoll, P., Magee, M., Mercier, J.L., Müller, B.C., Paquin, C., Rajendran, K., Stephansson, O., Suarez, G., Suter, M., Udias, A., Xu, Z.H., and Zhizhin, M., 1989. Global patterns of tectonic stress. Nature, 341:291-298.

Date of initial receipt: 16 September 1996

Date of acceptance: 30 April 1997

Ms 159SR-026 